\title{
Managing an expected home death
}

$\mathrm{T}$ he siren of the ambulance grows louder as it nears your home and you realize you've made a mistake. But it's too late. In a moment of panic, you dialed those three digits - 911 - and triggered a system. Soon paramedics are rushing through the front door and into the bedroom where your grandfather lies beneath his favourite blanket, without breath, without pulse, finally at rest after a fight with cancer that lasted a year but seemed like a decade.

The paramedics attempt to coax life back into the body, a futile effort, and yet, despite your pleas for them to stop, they persist. Then you hear more sirens. Seconds later, you are standing in your driveway, a police officer peppering you with questions, and neighbours, curious about the commotion, peering at you through slits in living room curtains. Your grandfather didn't want this. You didn't want this. Nobody wanted this.

So much for a peaceful death at home.

This is a scenario no family wishes to experience, which is why, according to experts in end-of-life care, people should have a plan in place for an expected death in the home. Otherwise, the family member present when the death occurs may be left wondering what to do and whom to call. For a planned death, there is no need to call anyone except the physician involved in the deceased's care and the funeral home director. Some people don't realize this, however, and inadvertently turn an expected event into a false emergency.

"If a family member panics at the time of death and calls 911, paramedics will respond. A paramedic has to initiate full resuscitation, even if it is obviously not the right thing to do. Police have to be called and the coroner has to be called. If you call 911, it is recognized as an unexpected event and an emergency," says Dr. Doris Barwich, program medical director of end-of-life care for Fraser Health in British Columbia. "People panic and think that calling 911 means they are just calling for help, but what they are doing is triggering a cascade of events."

To assist families caring for termi-

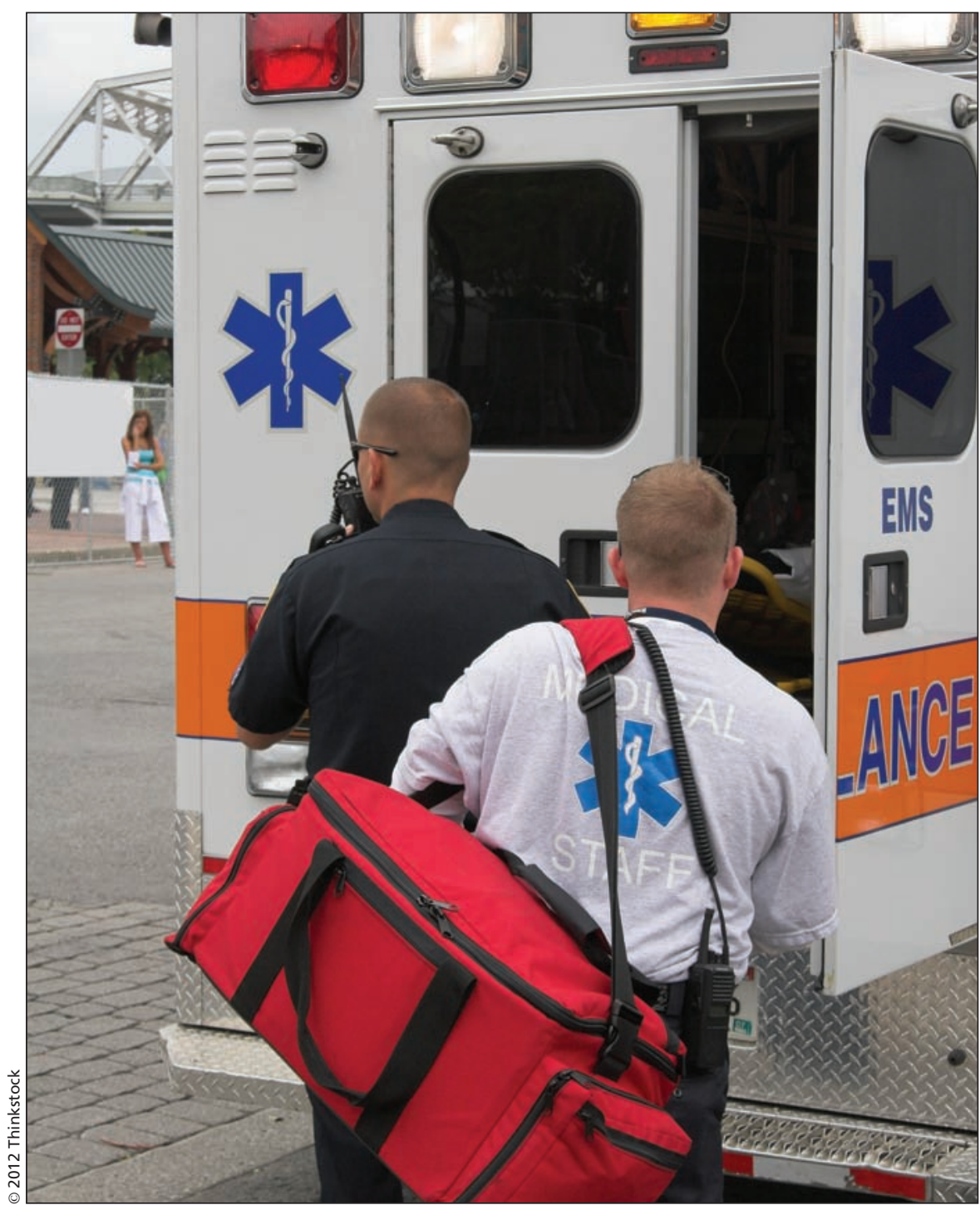

For a planned death, there is no need to call anyone except the physician involved in the deceased's care and the funeral home director. Some people don't realize this, however, and inadvertently turn an expected event into a false emergency.

nally ill relatives, some provinces have published guidelines on how to manage an expected home death, including Nova Scotia (www.gov.ns.ca/health/reports /pubs/PFEDH_brochure.pdf), Prince Edward Island (www.gov.pe.ca/photos /original/hss_homedeath.pdf) and Manitoba (www.cpsm.mb.ca/guidelines /gdl1600.pdf). The instructions are similar, for the most part, informing families to complete forms indicating a death in the home is imminent (to be sent to parties involved in the care of the patient and the eventual transport of the body, including the home care services provider and the funeral home) and to notify the funeral home when death appears near, while cautioning against calling the police, a coroner or emergency services.

Barwich prepared the protocol for British Columbia, which states that a "No Cardiopulmonary Resuscitation" form should be completed (www.health .gov.bc.ca/hcc/pdf/expected_home_death .pdf). Ideally, a physician or nurse should visit at the time of death, but if a family decides to contact the funeral home directly without consulting a health care professional, they must also possess a "Notification of Expected Death" form. This document, to be completed by a 
physician prior to the death, verifies that the death was natural and expected, that the family agreed to wait at least one hour after breathing stopped to call the funeral home to remove the body, and that the doctor or a designate will sign the medical certificate of death, required by all provinces to indicate the cause of death, within 48 hours.

This information is required to ease the minds of funeral home directors, who have at times expressed reluctance to retrieve a body without confirmation of death from a physician or nurse. After all, there have been rare incidents, notes Barwich, when funeral home employees have retrieved people who, despite appearing dead, still had some living to do. Having documentation in order prior to an expected death is especially helpful in remote communities, where nurses or physicians may not be available to visit a home until many hours after the time of death.

"You could have a dead body in the home for 14 hours if the funeral home wants to wait for a pronouncement of death," says Barwich. "Families were told that everything would be fine, to keep the room cold, but some families would get uncomfortable."

The idea that a doctor must pronounce death before a body can be retrieved from a home is a misconception, says Dr. John Butt, a private consultant in forensic pathology and a former chief medical examiner for both Alberta (1977-93) and Nova Scotia (1996-99). "The pronouncement of death is not a legal obligation. It is not required. On the other hand, it could be arranged with a physician because the family might not understand the signs of death and it would be wrong to call an ambulance," says Butt. "If you put a 911 call in, there is a possibility you will get sirens and lights and that ends up being anathema to the family."

Another misconception is that families must notify the police before an expected death in the home, though some doctors, and even some police officers, appear to believe this is required. "I've seen situations, in smaller communities, where police felt it was good housekeeping to know of every death in the community, but that kind of zeal only leads to complications," says
Butt, adding that there is no need for a grieving family to add discussions with police to its list of duties if the death wasn't sudden or suspicious.

It's important that health care providers help terminally ill patients and their families understand how to manage an expected death, and it will only become more important as Canadians become increasingly involved in decisions about their end-of-life care, says Dr. Terry Babick, deputy registrar of the College of Physicians and Surgeons of Manitoba.

"More and more people are opting to exercise the option of dying at home," says Babick. "To me, the logical extension is that they not be taken to an emergency department." - Roger Collier, CMAJ

CMAJ 2012. DOI:10.1503/cmaj.109-4101

\section{More news online}

Overhauling health care Down Under: Few developed nations in recent history have sought such systemic reform to its health care system as Australia, which over the course of the past four years has squabbled over jurisdictional issues, funding, primary care reform and a host of other issues in a bid to implement its most substantial overhaul of health care since universality was introduced in 1975 (www.cmaj.ca/lookup/doi /10.1503/cmaj.109-4099). — Tanalee Smith, Adelaide, Australia

Physicians open to ideas on how to assess and discuss fitness to drive: Physicians appear eager to explore new ideas on how to broach the touchy subject of driving competency with older patients (www.cmaj.ca /lookup/doi/10.1503/cmaj.109-4105). — Roger Collier, CMAJ

The rhythms of the Rock: Newfoundland and Labrador has become a bit of a staging ground on which genomics is reconfiguring the discipline of cardiology (www.cmaj.ca/lookup/doi/10.1503/cmaj.109-4102). — Stephen Strauss, Toronto, Ont.

The heartbeat of a First Nation: Genetic testing has resulted in a diagnostic paradigm shift for a rare heart arrhythmia known as Long QT Syndrome that has bedevilled about 1 in 90 of the Gitxsan First Nation in British Columbia (www.cmaj.ca/lookup/doi/10.1503/cmaj.109-4103). — Stephen Strauss, Toronto, Ont.

The all-clear signal for rare heart arrhythmias: Clinicians argue that the advent of genetic testing has allowed for early identification of carriers of rare heart arrhythmias and the subsequent prescription of preventive therapeutics, thereby diminishing patient fears that they're at risk of keeling over (www.cmaj.ca/lookup/doi/10.1503/cmaj.109-4104). Stephen Strauss, Toronto, Ont.

Are you kidding, doc?: Medical regulatory authorities that fail to conduct criminal records checks on physicians before issuing licenses to practice are either "negligent" or "ridiculously naive," patient advocates say (www.cmaj.ca/lookup/doi/10.1503/cmaj.109-4115). — Lauren Vogel, CMAJ

Medical privacy breaches rising: Concerns about medical privacy are spiralling as a result of a whopping increase in breaches of privacy involving health records of patients (www.cmaj.ca/lookup/doi/10.1503/cmaj.109-4116). - Roger Collier, CMAJ

CMAJ 2012. DOI:10.1503/cmaj.109-4119 cmaj.ca 